\title{
Sistemas de control financiero y su evolución en Ecuador
}

\author{
Victor Granda Aguilar*
}

\section{RESUMEN}

Partiendo del carácter integral que, en la doctrina y en la legislación e instrumentos internacionales, tiene actualmente el control externo, técnico-financiero y administrativo de los recursos públicos, este artículo se refiere a los principales sistemas de control existentes a nivel internacional: Tribunal de Cuentas y Contraloría, y, en ese contexto, describe la evolución del sistema de control financiero en Ecuador, desde inicios de la República hasta la actualidad, poniendo en evidencia el retroceso histórico que representa la adopción de reformas legales en el gobierno del presidente Rafael Correa y de enmiendas constitucionales aprobadas por la Asamblea Nacional en diciembre de 2015, que eliminan algunas potestades de la Contraloría y, en especial, el control de gestión y las facultades de establecer responsabilidades sobre el mismo.

Palabras clave: Tribunal de Cuentas, Contraloría, control contable, control financiero integral, control de gestión, enmiendas constitucionales.

\section{ABSTRACT}

Considering the current holistic character of the technical-financial and administrative extern control system of the public resources management present in doctrine, legislation and international instruments, this article analyzes the main control systems that can be identified at international level: Court of Auditors and General Comptroller. In this context, this article studies the evolution of the Ecuadorian system of control from the beginnings of the Republic to the present, showing the historical backward that the legal amendments promoted by the President Rafael Correa and the constitutional amendments approved by the National Assembly in December, 2015, represent because of the elimination of some powers of the General Comptroler's Office, especially in order to determine responsibilities on the management of public resources.

KEYWORDS: Court of Accounts, Comptroller, accounting control, comprehensive financial control, management control, constitutional amendments.

\footnotetext{
* Docente de planta del Área de Derecho de la Universidad Andina Simón Bolívar, Sede Ecuador.
} 


\section{EL CARÁCTER INTEGRAL DEL CONTROL FINANCIERO EN LOS SISTEMAS DE CONTROL}

i consideramos la interrelación histórica que existe, desde sus orígenes, entre el $\checkmark$ Derecho administrativo y el Derecho financiero o de la hacienda pública, ${ }^{1}$ encontramos un punto de confluencia objetiva de las dos disciplinas, en las normas y regulaciones relativas al control externo: económico, técnico-financiero y administrativo, que realizan en la actualidad los diferentes sistemas de control a las entidades que gestionan y disponen de recursos públicos.

Uno de los principales tipos de control externo, en el Estado democrático contemporáneo, es el financiero-administrativo, que, al ser ejecutado por un órgano especializado del Estado, teóricamente independiente y autónomo de los órganos e instituciones en los que se va a ejercer la fiscalización, tiene más bien una connotación técnica y profesional y una dimensión integral, ya que la evaluación de la actividad financiera del Estado necesariamente debe referirse, en la actualidad, no solo al buen y honrado usos de los recursos públicos, sino también a la calidad del gasto y a la eficiencia y eficacia de la gestión. ${ }^{2}$ Los sistemas técnicos económico-financieros de control externo de las administraciones públicas surgieron, según constatación histórica, como instrumentos auxiliares de la función de control político de los congresos, asambleas o parlamentos, y, en algunos casos, adquirieron luego autonomía relativa o total de aquellos, como órganos "extra poderes" del Estado o conformando una nueva función estatal, como ocurre actualmente en Venezuela, Bolivia y Ecuador. Sin embargo, lo esencial de ellos es la naturaleza de la actividad de control que realizan, acorde con las necesidades actuales de la sociedad y de los estados. Estos sistemas técnicos de control externo incluyen varios procedimientos y modalidades de distinta naturaleza; en la actualidad, los preferentes son las "auditorias", que pueden concentrarse en asuntos relacionados con: la legalidad y el cumplimiento de las normas; el uso de los recursos y los aspectos económico-financieros; la eficiencia y eficacia en la gestión administrativa para analizar los procesos, los procedimientos y sus resultados; el impacto medioambiental en las diferentes actividades y en los proyectos que se realizan y el examen de las obras públicas que se encuentran en ejecución, en las cuales se analiza su calidad y tecnología y las aplicaciones científicas adoptadas en ellas, además de sus costos e impacto económico-financiero y sus resultados en la gestión.

1. Andrea Amatucci, "La enseñanza del derecho financiero en Italia y España”, FORO: Revista de Derecho, No. 1 (2003).

2. Mario Garcés San Agustín, "El control económico-financiero en el ámbito de la Administración General del Estado", en Alberto Palomar y Mario Garcés, dir., La gestión de los Fondos Públicos: Control y Responsabilidades (Pamplona: Thomson Reuters/Arazandi, 2013). 
El control técnico global que realizan los órganos de control especializados algunos lo denominan "control gubernamental" o "control integral" y, cuando se refiere a uno solo de sus aspectos, se lo identifica de manera específica con el asunto o dimensión del mismo, a los que se refiere como "examen especial", sin abstraerse de su contexto integral o global cuando se establecen las conclusiones y los correctivos institucionales y personales que se estimen necesarios. ${ }^{3}$

El control financiero propiamente dicho tiene una connotación especial en el ámbito estricto del Derecho financiero, pues está relacionado con mayor precisión en la formulación, ejecución y evaluación del presupuesto, el endeudamiento público y la naturaleza de los ingresos y los gastos públicos. Sin embargo, en la actualidad, se le otorga una dimensión más amplia relacionándola con el control integral de la actividad administrativa, para determinar si la gestión económica-financiera de las instituciones públicas y de los funcionarios se ajusta a los principios de legalidad, economía, eficiencia y eficacia, como así lo recomiendan, además, las normas de auditoría internacional y los organismos que agrupan a nivel regional o mundial a las entidades superiores de control o fiscalización. ${ }^{4}$

Fernando Pérez Royo dice que el control de eficacia es una subespecie del control económico y financiero, que se ejerce "mediante el análisis del coste de funcionamiento y del rendimiento o utilidad de los respectivos servicios o inversiones, así como del cumplimiento de los objetivos de los correspondientes programas". ${ }^{5}$ Una auditoría financiera integral, necesariamente, tiene que referirse a la eficacia y eficiencia de la gestión de la administración y sus resultados.

Existen, de manera general a nivel internacional, dos sistemas o estructuras principales de control: unipersonales o pluripersonales para el ejercicio "técnico" del control externo, especialmente financiero, administrativo y de gestión de los presupuestos y de la actividad pública: el sistema europeo y pluripersonal de Tribunales de Cuentas y el sistema externo unipersonal de Contraloría de origen norteamericano, que tienen su aplicación histórica en Ecuador, con sus correspondientes connotaciones, como lo veremos a continuación.

3. Del Sistema de Control Externo (artículos 18-28), Ley Orgánica de la Contraloría General del Estado (Ley No. 2002-73).

4. Normas ISSAI y Directrices de Auditoría Financiera de la INTOSAI para la Buena Gobernanza (INTOSAIGOV). Disponible en 〈www.intosai.org〉; 〈www.olacefs.com〉.

5. Fernando Pérez Royo, Derecho Financiero y Tributario Parte General, 9a. ed. (Madrid: Civitas, 1999$), 394$. 


\section{EL SISTEMA EUROPEO DE TRIBUNAL DE CUENTAS}

El Tribunal de Cuentas tiene una larga historia en los países europeos. En el caso español existió previamente la figura del Contador y de la Contaduría Mayor de Cuentas para llevar y registrar las cuentas de la hacienda real, y, desde 1718, Felipe V utilizó por primera vez la designación Tribunal de Cuentas, que se conserva, con ciertos intervalos, hasta nuestros días y cuyo nombre se ha extendido a otros países de la Unión Europea y del mundo, si bien sus funciones y atribuciones no son las mismas, pues se han modificado a lo largo de la historia, de acuerdo con las circunstancias de cada país.

A este sistema se lo conoce también como sistema francés o de control jurisdiccional-administrativo para referirse a la Corte de Cuentas, creada en 1807 por Napoleón I, que posee una estructura y competencias similares a las del Consejo de Estado y ejerce, además de sus potestades jurisdiccionales y de fiscalización, un intenso control administrativo que se ha incrementado en las últimas décadas con reformas en los sistemas de contabilidad y de gestión. ${ }^{6}$

Desde sus orígenes hasta la actualidad, con ciertas modificaciones en el tiempo, el Tribunal y las Cortes de Cuentas conservan un doble carácter gubernativo-administrativo y jurisdiccional, si bien la influencia del sistema de control anglo-norteamericano, de gran difusión en la globalización capitalista contemporánea, ha reforzado sus atribuciones administrativas de fiscalización de la actividad económica-financiera. En algunos países se crearon además otros órganos, agencias o departamentos que realizan, exclusivamente en el ámbito administrativo-financiero, control externo.

El control que efectuaba inicialmente el Tribunal de Cuentas en España, desde su creación se refería al registro de ingresos, gastos y a la distribución y comprobación de las operaciones realizadas por los funcionarios de la Hacienda Real, por lo que la fiscalización esencialmente tenía una naturaleza contable y personal. Con la implantación del sistema constitucional, se estableció la obligación de que la Contaduría y luego el Tribunal de Cuentas presenten a las Cortes un finiquito anual de las mismas para su aprobación y, si bien inicialmente la jurisdicción contable se trasladaba a la Función Judicial, desde 1931 se definió al Tribunal de Cuentas de la República como un "órgano fiscalizador de la gestión económica", que "dependerá directamente de las Cortes y ejercerá sus funciones por delegación de ellas en el conocimiento y aprobación de las cuentas del Estado". ${ }^{7}$ Durante el régimen franquista (1936-1975) el Tribu-

6. Carlos Giuliani Fonrouge, Derecho Financiero, vol. I, obra actualizada por Susana Navarrine y Rubén Asorey, 7a. ed. (Buenos Aires: Depalma, 2001).

7. Art. 120 de la Constitución de la II República de 1931. 
nal de Cuentas mantuvo su carácter administrativo y jurisdiccional pero bajo la tutela y control total del Jefe de Estado.

El sistema de control pluripersonal externo, de cinco, siete o nueve jueces, ejercido por medio de un Tribunal de Cuentas de carácter económico-administrativo y jurisdiccional, para examinar el uso correcto y eficiente de los recursos públicos y establecer, si fuere del caso, responsabilidades administrativas y civiles, se encuentra reconocido en las constituciones de varios países europeos (Alemania, Italia, Bélgica, Grecia, Austria, Portugal, etc.); latinoamericanos (Brasil, Argentina, Colombia, Uruguay, Paraguay, etc.); y también en sistemas regionales de integración como la Unión Europea. Se trata de órganos de "relevancia constitucional" o "convencional", independientes de las otras estructuras de poder o relacionados con los parlamentos, para ejercer control externo a las estructuras administrativas, con obligación de informarlos de sus actividades y de los resultados de aquel y que se homologan a las Entidades Fiscalizadoras Superiores (EFS) que están estructuradas a nivel internacional.

En el caso de la Unión Europea, en 1975, mediante el Tratado de Bruselas se creó el Tribunal de Cuentas Europeo, que inició sus actividades en Luxemburgo en 1977 y se perfeccionó, como institución de pleno derecho, con el Tratado de Maastricht el 1 de noviembre de 1993, con la finalidad de controlar los ingresos y gastos que se manejan en la Comunidad, en los países miembros y en cualquier organismo creado por esta, así como su uso y la gestión que con ellos se realice. El control que efectúa es externo, a posteriori, permanente y se concreta en actos de fiscalización y auditorías sobre la legalidad, las reglas contables y una evaluación de una "buena gestión financiera", de su economía y de su eficacia y eficiencia administrativas, aplicando las normas básicas de fiscalización de la INTOSAI y en coordinación y colaboración con los Tribunales de Cuentas de los países miembros. ${ }^{8}$

Este sistema de control de legalidad y oportunidad, por medio del Tribunal de Cuentas, ha recibido en España una serie de reparos sobre su falta de independencia y, por lo tanto, de su ineficacia como órgano fiscalizador de las cuentas y de conocidos casos de corrupción y de su impotencia en el control de la gestión económica de las administraciones públicas, como resultado del origen de su nombramiento por parte de las mayorías partidistas que controlan las Cortes Generales y el gobierno. De igual manera, se cuestiona su incompetencia para controlar asuntos económicos-financieros de trascendencia, como la estabilidad presupuestaria y el equilibrio de las finanzas públicas de un país o de la región, lo que ha dado lugar al surgimiento de nuevas iniciativas como las de crear, tanto a nivel nacional como regional, nuevos organismos

8. Yolanda Gómez Sánchez, El Tribunal de Cuentas: el control económico y financiero externo en el ordenamiento constitucional (Madrid: Marcial Pons, 2001). 
de supervisión externa de las reglas fiscales, como la Autoridad Independiente de Responsabilidad Fiscal en España, cuyo propósito es el de evitar colapsos económicos y bancarios, como los ocurridos luego de la reciente crisis financiera de 2008. ${ }^{9}$

El profesor Fernández Ajenjo expone dos criterios sobre esta controversia. Algunos autores estiman que, dada la dependencia del Tribunal de Cuentas a la función de control parlamentario sobre la legalidad y eficacia en la gestión de los recursos públicos de las administraciones públicas, y al carecer de facultades suficientes en las labores de fiscalización y enjuiciamiento, su papel en la lucha anticorrupción es limitado, pues se reduce a "detectar y denunciar los denominados por Nieto de Alba 'riesgos morales', correspondiendo a las autoridades del orden penal y administrativo su represión y a las autoridades legislativas su corrección normativa". Otros consideran que dicho órgano máximo de control externo es clave para la lucha anticorrupción ya que los "actos defraudatorios de los intereses colectivos suponen, en la mayor parte de las ocasiones, un perjuicio a los intereses financieros públicos", lo que le permite "detectar, en primera instancia, las actividades irregulares producidas a través de sus unidades de control en el ejercicio de la función fiscalizadora" para, luego, "ser objeto, en segunda instancia, de enjuiciamiento contable, cuando se deba resarcir económicamente al erario público". ${ }^{10}$

Sin embargo de los cuestionamientos y controversias anteriores, se reconocen en la actualidad aciertos al Tribunal de Cuentas en el trámite de los procedimientos jurisdiccionales-contables por medio de salas que examinan "las cuentas que deben rendir quienes recauden, intervengan, administren, custodien, manejen o utilicen bienes, caudales o efectos públicos", ${ }^{11}$ y también en su labor fiscalizadora, que no solo se refiere a la legalidad sino a la eficacia de la actividad administrativa; al uso de la técnica de la auditoría pero con debilidades en el establecimiento de indicios de responsabilidad; al cumplimiento de su función de asesoramiento al parlamento y al aporte en la fiscalización forense que contribuye al enjuiciamiento contable y aún judicial, etc.

Martín Queralt y otros estudiosos del Derecho financiero sostienen que la función fiscalizadora de los Tribunales de Cuentas tienen un contenido "más amplio" que la que se realiza como "control interno" ya que no se restringe al control de legalidad, sino también al de oportunidad en la gestión económica-financiera y presupuestaria del sector público, para evaluar la "buena gestión", esto es, la "eficiencia, racionalidad y aprovechamiento máximo de los recursos que el legislativo mismo puso a disposi-

9. Ley Orgánica 6/2013, de 14 de noviembre, de creación de la Autoridad Independiente de Responsabilidad Fiscal.

10. José Antonio Fernández Ajenjo, El control de las administraciones públicas y la lucha contra la corrupción (Pamplona: Civitas/Thomson Reuters, 2011), 409 y 410.

11. Miguel Ángel Martínez Lago y otros, Lecciones de Derecho Financiero y Tributario, 11a. ed. (Madrid: Iustel, 2015), 227. 
ción del ejecutivo". Dicen también que su cobertura es "ilimitada" porque su control puede extenderse a todas las administraciones públicas y a todos los órganos que dispongan de recursos públicos y resaltan los efectos de la fiscalización del Tribunal que se expresan en la censura conforme o disconforme de las cuentas, en cuyo caso las irregularidades o delitos se someten a la jurisdicción contable o penal, según sea el caso. ${ }^{12}$

Es necesario precisar que la jurisdicción que ejercen los Tribunales de Cuentas no es la ordinaria, sino una jurisdicción contable especial destinada a reparar o restituir o indemnizar daños (responsabilidad civil) ocasionados al Estado o a las administraciones públicas, en materia económica y presupuestaria y de gestión, por parte de funcionarios, autoridades y personas que perjudiquen lo recursos y bienes públicos locales, nacionales y regionales, sin que esta atribución sea incompatible con otras que corresponden a la jurisdicción penal, disciplinaria y contencioso administrativa, dependiendo de la naturaleza de las infracciones, delitos y de las responsabilidades que se establezcan sobre ellas.

Al tener calidad jurisdiccional, los Tribunales de Cuentas, sus procedimientos y enjuiciamientos en los tradicionales "juicios de cuentas" deberán observar las garantías comunes constitucionales de todo proceso judicial, si bien para algunos tratadistas, como Pérez Royo, dicha función jurisdiccional contable permanece, en esos términos, más como un "residuo histórico". ${ }^{13}$

Como se puede advertir, el sistema de control mediante Tribunales de Cuentas, en todos los países que fue adoptado, evolucionó de un control contable a uno de auditoria que incorpora evaluaciones y recomendaciones integrales, relacionadas con la eficiencia, la gestión y los resultados de la misma. El carácter jurisdiccional de las resoluciones de estos Tribunales, en materia de responsabilidad civil, les otorga mayor fuerza obligatoria en la recuperación de recursos públicos o en la satisfacción de daños ocasionados a las entidades estatales.

Sin embargo, según nuestra opinión, la restitución económica por daños y perjuicios o pagos en exceso de los funcionarios o de terceros a las administraciones públicas, bien pueden ser solventados con mayor agilidad con procedimientos administrativos y no jurisdiccionales. No se requiere mantener procedimientos y ritualidades tradicionales de carácter "jurisdiccional" o "para-jurisdiccional" para establecer y tramitar responsabilidades y hechos sobre recursos públicos que, contable y administrativamente, se pueden determinar y recuperar con celeridad, claridad y exactitud.

12. Juan Martín Queralt, Carmelo Lozano, José Tejerizo y Gabriel Casado, Curso de Derecho Financiero y Tributario (Madrid: Tecnos, 2011), 794-5.

13. Pérez Royo, Derecho Financiero y Tributario Parte General. 


\section{EL SISTEMA EXTERNO UNIPERSONAL DE CONTROL O CONTRALORÍA}

El sistema externo de control unipersonal, mediante un órgano unipersonal, tiene origen anglo-norteamericano, pues en Gran Bretaña se inició como control parlamentario que, al no poder ser realizado a plenitud de manera directa, se lo delegó desde 1832 a un organismo técnico como el Departament of Exchequer and Audit, dirigido por un Comptroller y Auditor General, que realizaba sus "test audit" o fiscalizaciones intensivas efectuadas mediante inspecciones sorpresivas que obligaban a las instituciones a mantenerse en orden y en permanente regularidad, los bienes y recursos a su cargo.

Este sistema de control se adoptó posteriormente en Estados Unidos en la administración de Woodrow Wilson, con técnicas originadas en el ámbito privado y gerencial, en las primeras décadas del siglo XX, como resultado de la crisis en la economía y en las empresas, luego de la primera guerra mundial.

Desde 1921 se estableció la estructura actual de control norteamericano, mediante el Budget and Accountig Act que creó el General Accounting Office y frente al cual se designó a un Comptroller General, nombrado primero por el Presidente por quince años y luego por el Congreso (1946), que es el responsable directo ante este por sus acciones de control administrativo, contable y de fiscalización, tanto de las dependencias administrativas como de las corporaciones estatales. ${ }^{14}$

Los sistemas de contabilidad y control externo en EE. UU. se perfeccionaron también como una respuesta estatal a los efectos desastrosos de la crisis del capitalismo moderno y del crack de la bolsa Nueva York en 1929, y como resultado de la irracionalidad del mercado y la falta de transparencia en las empresas. En 1933, mediante Ley, se estableció en Estados Unidos un nuevo modelo regulador de las empresas y de transparencia en sus cuentas, mediante la intervención de técnicos auditores.

Durante los gobiernos de Franklin Delano Roosevelt se insistió en un eficiente control de las empresas y del sistema financiero, para superar el descalabro económico generalizado y, mediante reformas administrativas y mecanismos de información y transparencia, se trasladó a la administración pública, las nuevas técnicas de "garantía de calidad", que incluían auditoría, evaluación, acreditación y certificación, en el ámbito de las instituciones estatales.

Más tarde, en 1960, se conformó en Estados Unidos la Corporate Social Responsability que incluía el control de la seguridad social y laboral, los derechos ambientales

14. Giuliani Fonrouge, Derecho Financiero. 
y los asuntos de raza y género, que luego fueron afinados con las reformas administrativas del presidente John F. Kennedy en los años siguientes. El sistema de control se perfeccionó con las modificaciones implementadas por las administraciones de Johnson, Nixon y, recientemente, con las políticas del presidente Barack Obama, siguiendo los sugestivos planteamientos de los administrativistas norteamericanos Cass Sunstein y Richard Thaler. ${ }^{15}$

Esta modalidad de control se impuso también en varios países latinoamericanos y luego sus técnicas se fueron adaptando paulatinamente en otros países de tradición jurídica continental, modificando las atribuciones de los Tribunales de Cuentas, o creando nuevos órganos de control y auditoría financiero-administrativos externos de carácter independiente.

Este sistema tiene como máxima instancia directiva autónoma de control y de auditoría un órgano unipersonal, el Contralor, que se encuentra supeditado inicialmente al Congreso, Asamblea u órgano legislativo, como auxiliar técnico de control externo a sus labores de control político, si bien su designación depende una vez de la Función Legislativa, otra del Presidente o de los dos a la vez.

Los sistemas de auditoría y evaluación, tanto en el sector privado como en el sector público, dan como resultado positivo, para el mercado, la sociedad y el Estado, transparencia y seguridad. Si no funcionan los indicados sistemas resulta evidente que crece la corrupción, la desconfianza y estallan escándalos, como ocurre en la actualidad, con los capitales de dudosa procedencia que se encuentran en "paraísos fiscales" y con catástrofes económicas y sociales, como las crisis internacionales de 2008 en Estados Unidos y desde 2009 en Europa, provocadas en buena parte por la falta de control del mercado hipotecario, de futuros y de derivados del sistema financiero internacional.

De manera acelerada, en la época actual de globalización, que "ha extrapolado" el modelo administrativo regulador y de control estadounidense, se ha ido generalizando en todo el mundo, este sistema de Contraloría o se han adoptado sus beneficios en la actividad de los Tribunales de Cuentas, tanto para desarrollar e incluir en el control de la administración pública los sistemas de eficiencia y eficacia asumidos de las empresas privadas, como para ejercer control sobre "nuevos derechos sociales, ambientales, de minorías, de riesgos laborales, derechos civiles y de discriminación positiva, etc.". ${ }^{16}$

15. Pilar Jiménez Tello, "Regulación a través de la evaluación: auditoría y calidad en las Administraciones Públicas", Revista Eurolatinoamericana de Derecho Administrativo 1, No. 1 (2015).

16. Ibíd., 3 . 


\section{LA EVOLUCIÓN DE LOS SISTEMAS DE CONTROL EN ECUADOR: DEL TRIBUNAL DE CUENTAS A LA CONTRALORÍA}

En su origen republicano en Ecuador, desde 1830 hasta 1863 y en las sucesivas Leyes de Hacienda, se establecieron, siguiendo las instituciones coloniales, primero una Contaduría General y luego Contadurías Departamentales, para examinar y finiquitar cuentas de funcionarios, cuyas decisiones podían ser apeladas ante el Ministerio de Hacienda. Desde 1863, la nueva Ley de Hacienda trasladó las atribuciones de las Contadurías al Tribunal de Cuentas, concebido este como un órgano jurisdiccional destinado a conocer y resolver sobre las cuentas que obligatoriamente debían presentar los funcionarios públicos nacionales y municipales, luego de llevar los correspondientes registros contables.

El Tribunal de Cuentas, organizado en dos salas, era designado de manera mixta por el Congreso Nacional y el Presidente, de igual manera que la Corte Suprema de Justicia. Los expedientes de cuentas concluían en sentencias o "vistas" que debían ser publicadas con la finalidad de que el "rindente" o su apoderado, o los ministros o los "revisores" puedan solicitar formalmente su revisión a la otra sala que no conoció el asunto, para que expida la sentencia o "revista" que corresponda y para que esta, finalmente, pueda ser impugnada ante la Corte Suprema, mediante los recursos de queja o de nulidad.

El Tribunal de Cuentas podía establecer, en sus decisiones, responsabilidades pecuniarias cobradas al funcionario involucrado, y legales a quien infrinja las normas, pudiendo ser sancionado con la destitución, suspensión de derechos y aun con prisión para que él o sus sucesores presenten las cuentas. Si el Tribunal encontraba indicios de la comisión de un delito cometido por el funcionario, la Sala debía trasladar el expediente al juez competente. ${ }^{17}$

El Tribunal de Cuentas con jurisdicción contable se mantuvo en Ecuador por sesenta y cinco años (65), con ciertas modificaciones efectuadas en 1912 y 1924, mientras estuvo vigente la Ley de Hacienda de 1863, expedida en el gobierno de Gabriel García Moreno y su conformación constó en las Constituciones de 1878, 1883, 1897 y 1906. El control se limitó fundamentalmente a los aspectos contables de la ejecución presupuestaria y del manejo de los recursos asignados y desembolsados por los funcionarios estatales en Quito, Guayaquil y Cuenca.

17. Ley de Hacienda de 21 de octubre de 1863. 


\section{LA CONTRALORÍA EN ECUADOR: DEL CONTROL DE CUENTAS AL CONTROL INTEGRAL}

En la estructuración de la Contraloría como sistema unipersonal de control unipersonal, que se introdujo en Ecuador y otros países de la región, tuvo incidencia activa la comisión asesora de expertos académicos financieros norteamericanos, presidida por Edwin Walter Kemmerer entre 1923 y 1931, que sugirió establecer un nuevo sistema monetario, bancario y financiero y estructurar otros órganos de control como las superintendencias y direcciones generales. En su labor de asesoría y supervisión se le permitió designar funcionarios extranjeros para ejercer el control de bancos, aduanas y contabilidad nacional.

En ese contexto, se creó en Ecuador en 1928, mediante nueva Ley de Hacienda, la Contraloría General de la Nación para la vigilancia del comportamiento fiscal y la contabilidad del gobierno, en sustitución de los Tribunales de Cuentas que funcionaban en Quito, Guayaquil y Cuenca, y se designó como primer Contralor General al norteamericano James H. Edwards, quien fue sustituido en 1929 por un contralor de nacionalidad ecuatoriana. ${ }^{18}$

En el sistema de control en Ecuador, que ejerce la Contraloría General de la Nación primero, y luego del Estado, desde 1928 hasta la actualidad, se pueden identificar tres momentos importantes. El inicial, de 1928 a 1974, en el que el control combina primero procedimientos internos y externos, centrando su vigilancia en los aspectos contables del ejercicio de las actividades de los funcionarios públicos sobre las que se establecen responsabilidades administrativas principalmente, a las que se agregan las reformas administrativas y de fiscalización adoptadas por el gobierno de Galo Plaza, con asesoría del Punto IV norteamericano, ${ }^{19}$ sobre el buen uso de los recursos públicos, involucrando no sólo a funcionarios sino también a las instituciones estatales.

Un segundo momento, de 1974 a 1998-2002, en el que se expide una Ley moderna en materia de control y administración financiera, la LOAFYC,${ }^{20}$ que contiene las normas que rigen la actividad financiera gubernamental (contabilidad, tesorería, presupuesto, etc.) a cargo del Ministerio de Finanzas y las que corresponden a la Contraloría General del Estado para regular los sistemas de control interno y externo y de gestión mediante auditorías; el establecimiento de responsabilidades y los recur-

18. Paul W. Drake, Kemmerer en los Andes (Quito: Banco Central del Ecuador, 1995).

19. Se conoce como Punto IV al programa de ayuda técnica y económica para el desarrollo, impulsado por EE. UU. en América Latina y en países subdesarrollados, a partir de la iniciativa del presidente Harry Truman, formulada en enero de 1949.

20. Ley Orgánica de Administración Financiera y Control, R. O. 337, 16 de mayo de 1977. 
sos administrativos y contenciosos que los ciudadanos pueden interponer frente a sus decisiones. Estas innovaciones no fueron recogidas a plenitud en la Constitución de 1979, como sí lo hizo la Constitución de 1998, que es el antecedente para la aprobación de la vigente Ley Orgánica de la Contraloría General del Estado (LOCGE) en junio de 2002.

Un tercer momento se inicia con la promulgación de la referida ley y se consolida con el contenido de la Constitución de 2008 que amplía inicialmente las funciones, atribuciones y autonomía de la Contraloría, cuyo titular es designado para cinco años, mediante un concurso promovido por una comisión especial de selección, sin una aparente intervención directa del Ejecutivo o de la función Legislativa, lo que es desmentido con la designación exclusiva de personas allegadas al régimen. La ampliación de funciones y atribuciones incluye, inicialmente, un concepto integral de control, el análisis de la gestión y la eficacia y eficiencia en el uso de los recursos públicos y se ve complementada con un mayor desarrollo del control interno en las instituciones administrativas, con el uso creciente de la tecnología y el control por procesos y resultados.

Sin embargo, este proceso progresista se ve interrumpido por las reformas constitucionales aprobadas mediante "enmiendas", en diciembre de 2015, y que se lo podría calificar como el inicio de un nuevo momento de incertidumbre y de solapado retroceso de la función de control, pues se elimina del ámbito de la Contraloría el análisis del cumplimiento de "objetivos" institucionales y se pretende reducir su actividad a un simple control económico a posteriori en el uso de los recursos públicos, manteniendo la posibilidad de que se puedan establecer sobre los funcionarios, responsabilidades administrativas y civiles y trasladar los indicios de responsabilidad penal a la Fiscalía para el correspondiente enjuiciamiento penal, todo ello en relación con el manejo de recursos, mas no por la gestión, como originalmente lo disponía la Constitución.

En el primer momento, cuando se sustituye el sistema de control jurisdiccional pluripersonal del Tribunal de Cuentas por el sistema unipersonal en 1928, la Contraloría no actúa exclusivamente en el ámbito administrativo externo bajo un régimen de auditorías, ni tampoco sus decisiones quedan sometidas al control contenciosoadministrativo o jurisdiccional. La Contraloría ejerció, en este período, atribuciones de manifiesto control de los recursos presupuestarios y otras de las que actualmente se encontrarían en el ámbito del "control interno", pues emitía pronunciamientos previos o concurrentes para la derogación de recursos públicos y manejo de bienes; certificaciones de disponibilidades de fondos, transferencia de partidas, etc.

En cuanto al control externo propiamente dicho, referente a los exámenes de cuentas, la Contraloría mantenía para sus decisiones, el tradicional carácter de jurisdicción contable que caracterizaba al Tribunal de Cuentas, para tener una mayor vigilancia sobre los funcionarios y el uso de los recursos públicos sin tomar en cuenta el desempeño institucional y de sus actividades administrativas. Su atribución se limitaba pues 
al examen contable y a "finiquitos" de la información financiera y de la ejecución del presupuesto que obligatoriamente los funcionarios debían hacerle conocer, para que se declare si el uso de los recursos fue o no el correcto. En cuanto a responsabilidades, la Ley, autorizaba al Contralor a trasladar a los jueces competentes los asuntos de carácter penal, además de destituir a funcionarios de sus cargos e imponer multas o anotarlas cuando eran impuestas por otras autoridades administrativas.

En la Constitución de 1946 consta (art. 149) que el Contralor General, designado por el Congreso, desempeñaba función jurisdiccional cuando conoce y sentencia cuentas que manejan los funcionarios públicos. Esta norma distorsionaba totalmente el carácter administrativo de este tipo de control y el ámbito propio de la jurisdicción contenciosa administrativa, que se encontraba en formación en Ecuador, desde las Constituciones de 1906, 1929 y 1945.

En 1951 se actualiza la legislación presupuestaria ${ }^{21}$ y en 1958 y 1961 se dictan normas para regular de mejor manera los asuntos contables, administrativos y financieros públicos, con asesoría del Punto IV de EE. UU. y la consultora Affaires Institute.

En 1963, durante el gobierno de la Junta Militar, frente al impacto de la Revolución cubana en América Latina, el gobierno norteamericano planteó su proyecto regional de Alianza para el Progreso que incluía la ejecución de tres reformas radicales: administrativa, tributaria y agraria. En la modificación administrativa se plantearon nuevos sistemas y estructuras administrativos para el sector público, como la Secretaría Técnica de la Administración, y más tarde la creación de otras dependencias con la finalidad de reformar la estructura y los procedimientos administrativos, ejecutar las reformas económico-sociales propuestas y "mantener una evaluación permanente del grado de eficiencia con que se prestan los servicios públicos". ${ }^{22}$

En la Ley que creó el Tribunal Fiscal (1959), y luego el Código Fiscal (1963), se le otorgaban competencia al primero para conocer recursos y emitir sentencias sobre resoluciones de la Contraloría General, relativas a responsabilidad económica en las Instituciones Públicas. ${ }^{23}$ En la Constitución de 1967 se modificó el nombre de Contraloría General de la Nación por Contraloría General del Estado y cuando se dictó la Ley de la Jurisdicción Contencioso Administrativa (1968), y en especial con el Decreto 1077 en 1973, quedó claro que correspondía al Tribunal Contencioso Administrativo conocer y resolver las resoluciones de la Contraloría. ${ }^{24}$ Pero es en 1975,

21. Ley Orgánica de Presupuesto, Decreto de Emergencia No. 538, R. O. 769, 21 de marzo de 1951.

22. Decreto-Ley 240, Registro Oficial 33, 20 de agosto de 1963, quinto considerando.

23. Ley 10, Registro Oficial 847, 19 de junio de 1959; Código Fiscal de 1963, R. O. 490, 25 de junio de 1963.

24. Ley 035-CL, Registro Oficial, 338, 18 de marzo de 1968; Decreto 1077, Registro Oficial 392, 17 de septiembre de 1973 . 
con la expedición del Decreto 611 y del Código Tributario (1975), que se completó el tránsito definitivo de la etapa jurisdiccional a la etapa propiamente administrativa de control externo ejercido por la Contraloría. ${ }^{25}$

Durante la dictadura militar del general Guillermo Rodríguez Lara, siguiendo las innovaciones administrativas y de control provenientes en especial de EE. UU., se dictaron varios decretos para organizar adecuadamente el control y la administración financiera de las instituciones públicas en Ecuador. La Contraloría propuso en 1974 el texto del Decreto 1065-A para implantar en el país un "control gubernamental moderno" mediante el cual se establecen dos sistemas: el control interno y la auditoría externa, reformando radicalmente la Ley de Hacienda de 1960. De acuerdo con este Decreto, a la Contraloría le corresponde "poner en funcionamiento en el sector público, un sistema integrado de administración financiera y control, capaz de servir al desarrollo del país y al empleo de los recursos humanos, materiales y financieros, de manera eficiente, efectiva y económica, evaluando periódicamente y velando en forma permanente por la correcta aplicación del mismo". ${ }^{26}$

Todos los cambios antes indicados y otros, resultado de la necesidad de agilizar la prestación de servicios públicos y el desarrollo socioeconómico del país, constan en la nueva Ley Orgánica de Administración Financiera y Control de $1976^{27}$ que establece un sistema integrado de presupuesto, de determinación y recaudación de recursos, de tesorería y contabilidad y de control.

Las reformas y la nueva Ley no solo autorizaron legalmente al contralor, desde 1974 y 1976, establecer un sistema más ágil que permita a las instituciones un control contable interno más eficaz de los recursos públicos, sino que agregaron, a la naturaleza tradicional del control, la innovación de ejercer un control integral, que asocie los asuntos financieros con los operacionales y de resultados en la gestión de la entidades públicas, además de la potestad de control en la determinación de ingresos y en el control interno y en el ejercicio de sus potestades normativa, asesora y correctiva.

Se trata de un sistema de control distinto al instaurado en el país en 1928 con la asesoría de Kemmerer, pues ahora el sistema tiene por objeto "las operaciones administrativas y financieras de la institución y no sólo las "cuentas" y, a la vez, "el sujeto del control es la entidad y, por consiguiente, de sus gestores empezando por los máximos ejecutivos, lo que contrasta con el sistema anterior, en el que el sujeto de

25. Decreto 611, R. O. 857, 31 de julio de 1975.

26. Decreto 1065-A, Registro Oficial, 668, 28 de octubre de 1974.

27. Ley Orgánica de Administración Financiera y Control, LOAFYC, R. O. 337, 16 de mayo de 1977. 
control era únicamente el rindente", ${ }^{28}$ sobre el cual se partía de una cierta presunción que habría cometido alguna "incorrección".

Por ello, vale enfatizar que el nuevo sistema de control se fundamenta en "la presunción de corrección" y en las "auditorías" y "exámenes especiales" financieros, operacional o de cualquier índole, que tienen la finalidad de promover reformas en la gestión administrativa de cada entidad u organismo, con "recomendaciones" que se convierten luego en obligaciones a ser cumplidas por los gestores de las entidad pública, independientemente de trasladar los indicios de responsabilidad penal a la Fiscalía y a los jueces competentes y de establecer las responsabilidades que se hayan fijado contra ellos o sus antecesores, en el ámbito administrativo y civil. Las auditorías se efectúan aplicando las normas "generalmente aceptadas", provenientes de Conferencias de Contabilidad y en general por los Contadores Públicos a nivel internacional.

El sistema de control financiero y control previsto en la LOAFYC se mantuvo en Ecuador hasta 2002 a cargo del Ministerio de Finanzas y de la Contraloría, que debían actuar coordinadamente, pues en varios casos se requerían informes previos e iniciativas conjuntas. En ese año se expidió la Ley Orgánica de la Contraloría General del Estado, ${ }^{29}$ dejando la administración financiera y presupuestaria y los otros asuntos de su organización y decisión internas en manos del Ejecutivo y del Ministerio de Finanzas.

La nueva Ley Orgánica de la Contraloría General del Estado, como exclusivamente lo disponía la Constitución de 1998 y la de 2008 hasta las "enmiendas" de fines de 2015, asigna a la Contraloría competencia administrativa del control externo e interno total o gubernamental, en sus diferentes dimensiones, contable, financiera, económica, administrativa, de operación, de gestión, ambiental, etc., sobre todas las entidades del sector público y de otros sectores que perciben fondos públicos, facultándole a la vez a ejercer potestades normativas, de asesoría en el ejercicio de sus funciones y a establecer las correspondientes presunciones de responsabilidad administrativa y civil, que están sometidas al control jurisdiccional contencioso administrativo en la función Judicial, y los indicios de responsabilidad penal para que sean trasladados a la Fiscalía General y dé inició a las acciones penales correspondientes.

28. Estudio introductorio a la Ley Orgánica de Administración Financiera y Control, SILEC. Disponible en «www. bolsadevaloresguayaquil.com».

29. Ley Orgánica de la Contraloría General del Estado. Ley No. 2002-73, Registro Oficial 595, 12 de junio de 2002. 


\section{RESTRICCIONES AL CONTROL FINANCIERO EN EL GOBIERNO DEL PRESIDENTE CORREA}

Durante el gobierno del presidente Rafael Correa (2007-2017), caracterizado por la concentración del poder, se introduce una serie de restricciones a los sistemas de control y en especial a las competencias de la Contraloría para emitir informes previos en los procesos de contratación pública y a su responsabilidad de control financiero que realizaban conjuntamente, hasta los inicios de su gobierno, la Contraloría General del Estado y el Ministerio de Finanzas, despojando al órgano de control externo de esa competencia, para trasladarla a órganos dependientes de la Función Ejecutiva.

En el Código Orgánico de Planificación y Finanzas (2010), se derogó la norma de la Ley de Presupuestos que confirió a la Contraloría de manera expresa el control previo, concurrente y posterior del presupuesto general del Estado. El Código, al referirse a la fase de seguimiento y evaluación de aquel, dice que esta comprende la medición de resultados físicos y financieros obtenidos y los efectos producidos, y que, de dicha evaluación y resultados -que incluyen, según el Reglamento, el cumplimiento de metas y objetivos, eficiencia y eficacia del gasto en programas, proyectos y actividades institucionales-, son responsables los titulares administrativos de cada entidad, los que enviarán, periódicamente, los informes al respecto al ente rector de las Finanzas Públicas, que es el Presidente, el ministro de Finanzas y la Secretaría Nacional de Planificación y Desarrollo (SENPLADES), para luego ser difundidos a la ciudadanía. ${ }^{30}$ Esto es, en dicho Código se excluye total y explícitamente a la Contraloría de sus labores de control del presupuesto general del Estado, anticipando la intensión posterior del Ejecutivo manifestada en las enmiendas constitucionales de 2015.

Para limitar la autonomía económica de la Contraloría y su financiamiento con el aporte del cinco por mil de los ingresos de las instituciones sometidas a su control, este fue sustituido en 2014 con una norma para que se financie su presupuesto "con la asignación que se le entregue a través del presupuesto general del Estado", en el que la función Ejecutiva tiene manejo absoluto en todas sus fases, si bien se agregó que la Contraloría puede obtener "recursos de autogestión". ${ }^{31}$

En el informe de rendición de cuentas de 2015, que presenta el contralor general del Estado, consta también la activa relación internacional del principal órgano de control externo del Estado con el Organismo Internacional de Entidades Fiscalizadoras Superiores (INTOSAI) al formar parte de su Comisión Financiera y Adminis-

30. Código Orgánico de Planificación y Finanzas Públicas, R. O. 306, 22 de octubre de 2010; Reglamento General del Código Orgánico de Planificación y Finanzas Pública, (DE-489) R. O. 329, 26 de noviembre de 2010.

31. Reformas al Código Monetario y Financiero, R. O.-2S 332, 12 de septiembre de 2014. 
trativa; con la Organización Latinoamericana y del Caribe de las Entidades Fiscalizadoras Superiores (OLACEFS), y con las Entidades Fiscalizadoras Superiores del MERCOSUR y EFSUR. En dichas entidades prospera también el concepto de que las auditorías y las acciones perfeccionadas que realizan en la actualidad los Entes Superiores de Fiscalización implican un sistema complejo en el que no solo se examinan los recursos estatales utilizados, sino la consecución de los objetivos institucionales. ${ }^{32}$

Con las enmiendas constitucionales impulsadas por el gobierno del presidente Correa y aprobadas en diciembre de 2015, se elimina del texto constitucional (artículo 211) la competencia de la Contraloría de controlar "la consecución de los objetivos de las instituciones del Estado" y se la limita a controlar "la utilización de los recursos estatales", lo que significa un retroceso histórico en la función y papel de la entidad, ya que la orientación actual de los procesos de auditoría en el mundo y en la región incluyen, necesariamente, una valoración no solo de la utilización de los recursos, sino también de la gestión y de los resultados de la administración, tomando en consideración los principios de eficiencia, eficacia y economía.

De igual manera se reforma también el artículo 212 de la Constitución que elimina la potestad de la Contraloría de determinar responsabilidades administrativas y civiles culposas e indicios de responsabilidad penal en los asuntos de "gestión". En otras palabras, la auditoría integral de uso eficaz de recursos y de gestión queda limitada a una fiscalización posterior sobre aquellos, eliminando la finalidad de poder establecer si esos recursos fueron bien, ética y eficientemente utilizados por la administración.

En el dictamen, emitido por la Corte Constitucional, sobre las enmiendas a los referidos artículos de la Constitución, se afirma que al delimitarse las competencias de las instituciones se "fortalece la institucionalidad", pues se determinan sus funciones y se evitan interferencias con otras entidades, como la Secretaría Nacional de Planificación y Desarrollo Social. Agrega también el dictamen que las modificaciones propuestas a los artículos 211 y 212 de la Constitución no menoscaban, reforman o modifican las atribuciones de la Contraloría General del Estado. ${ }^{33}$

La Comisión Ocasional de Enmiendas de la Asamblea Nacional, en su informe para segundo debate, argumenta que la Secretaría de la Administración Pública es la encargada de realizar el control de las entidades del Ejecutivo "para la consecución del Plan Nacional del Buen Vivir" y que "los productos del control de la gestión que realiza la Secretaría son insumos para que el Presidente de la República rinda cuentas al Legislativo, subsecuentemente, el Legislativo ejerce su atribución constante de fis-

32. Rendición de Cuentas del Contralor General del Estado, Carlos Pólit, marzo de 2016.

33. Dictamen de Constitucionalidad sobre las Enmiendas No. 001-14-DRC-CC, 31 de octubre de 2014, Gaceta Constitucional No. 009, 10 de noviembre de 2014. 
calizar los actos del Ejecutivo". Y, agrega, que "el rol primigenio de la Contraloría es el de ser 'juez de cuentas" ". ${ }^{34}$

En la rendición de Cuentas que la Contraloría General del Estado presenta, en marzo de 2016, su máximo personero manifestó, de manera categórica:

La Constitución de Montecristi es una síntesis del proceso histórico de construcción de la República, [ella] condensa la evolución de la Contraloría General del Estado, plasmada en una concepción moderna y eficaz en el control de los recursos públicos. Hasta diciembre de 2015, la Constitución atribuía a la entidad fiscalizadora superior una obligación de control integral de los recursos públicos, en dos vías: primero, sobre su utilización en la adquisición de bienes, construcción de obras y prestación de servicios, individualmente considerados; y, en segundo lugar, en base del análisis del cumplimientos de los objetivos, planteados en el marco de sus competencias, de todas las instituciones públicas. En varias ocasiones, las autoridades de la institución expresaron sus argumentos respecto a las enmiendas e indicaron que modifican las competencias del organismo de control. La oposición a los cambios aprobados por el legislativo se justifica ante la ausencia de otra institución, designada constitucionalmente, que asuma la competencia de auditar la gestión y la consecución de los objetivos de los organismos del Estado. Las facultades actuales de la CGE reflejan el perfeccionamiento continuo de la auditoría en el país y concuerdan con el trabajo que realizan las EFS de la región y del mundo. Desde el punto de vista técnico, el control de los recursos públicos no es un conjunto aislado de actividades. Se trata de un sistema complejo y el análisis de la consecución de los objetivos institucionales, que requiere la utilización de fondos estatales, es una parte esencial del proceso, por lo que la defensa de la institucionalidad responde a la necesidad de sostener un adecuado control, a través de medios técnicos que permiten fiscalizar con resultados correctos. ${ }^{35}$

Hacia el futuro, queda clara la decisión del régimen que seguramente difícilmente será alterada por la Corte Constitucional: la evaluación de gestión de los órganos de la función Ejecutiva será realizada por la propia administración, por medio de la Secretaría Nacional de la Administración Pública o por la Secretaría de la Presidencia, la Secretaría Nacional de Planificación de Desarrollo Social y algunas dependencias del Ministerio de Finanzas, todas con competencias asignadas por el Presidente de la República, mediante simple decreto ejecutivo y sin jerarquía de ley, y no por un órgano técnico externo y especializado, como lo es la Contraloría General del Estado, que de acuerdo con la Constitución podía establecer responsabilidades personales, no solo

34. Informe para segundo debate de la Comisión Ocasional de Enmiendas Constitucionales, 23 de noviembre de 2015. Disponible en 〈www.asambleanacional.gob.ec/sites/default/files/field/image/enmienda8.jpg〉.

35. Rendición de Cuentas del Contralor General del Estado, Carlos Pólit, marzo de 2016. 
por el manejo de los recursos públicos sino por la calidad de la gestión y el cumplimiento de objetivos en las actividades y proyectos de la administración.

Esto es, con las enmiendas constitucionales se consagra un retroceso importante en el Derecho de control en Ecuador, pues en cuanto a las atribuciones que se asignan a la Contraloría General del Estado, como órgano de control externo, se pretende retornar al restringido control contable otorgó la Ley de Hacienda en 1863 al entonces Tribunal de Cuentas, en el gobierno del presidente Gabriel García Moreno. ${ }^{36}$

\section{CONCLUSIONES}

Los sistemas de control a nivel internacional, sea mediante los actuales Tribunales de Cuentas y otros órganos independiente de control administrativo de gestión, o mediante las Contralorías como órganos de control externo e interno, atribuyen al control administrativo y financiero externo competencias integrales tanto sobre el uso y disposición de los recursos públicos como sobre su utilización eficiente y eficaz en los resultados y gestión de los órganos y funcionarios que ejercen potestades públicas.

En Ecuador se ha transitado históricamente del control contable que realizaba el Tribunal de Cuentas hasta 1928, al control externo integral, técnico-financiero y administrativo que fue asumiendo la Contraloría General del Estado entre 1998 y 2010 y que estaba destinado no solo a dar cuenta del buen y honrado uso de los recursos públicos, sino a analizar además la calidad y eficiencia del gasto y sus resultados para establecer los correctivos que sean necesarios en las entidades estatales.

El gobierno del presidente Correa, con las reformas introducidas en el Código de Planificación y Finanzas (2010) sobre las atribuciones de la Contraloría en materia de control del Presupuesto del Estado y su autonomía financiera (2014), y, especialmente con las enmiendas constitucionales aprobadas en 2015, pretende eliminar, de manera definitiva, el control sobre la gestión y operación administrativas y financieras para trasladarlas a órganos internos dependientes de la función Ejecutiva. Se persigue, por lo tanto, reducir al órgano de control de Ecuador al rol primigenio de ente de "control de cuentas", eliminado los avances conceptuales sobre auditoría; los fines correctivos que cumplen las acciones de control y el papel de órgano de control financiero externo e integral asignado a las Entidades Superiores de Control por los convenios internacionales que las rigen y las normas originales de las Cartas Constitucionales de 1998 y 2008 .

36. Ley de Hacienda de 21 de octubre de 1863. 


\section{BIBLIOGRAFÍA}

Amatucci, Andrea. "La enseñanza del derecho financiero en Italia y España". Foro: Revista de Derecho, No. 1 (2003).

Drake, Paul W. Kemmerer en los Andes. Quito: Banco Central del Ecuador, 1995.

Fernández Ajenjo, José Antonio. El control de las administraciones públicas y la lucha contra la corrupción. Pamplona: Civitas/Thomson Reuters, 2011.

Garcés San Agustín, Mario. "El control económico-financiero en el ámbito de la Administración General del Estado". En Alberto Palomar, Mario Garcés y otros, directores, La gestión de los fondos públicos: control y responsabilidades. Pamplona: Thomson Reuters Aranzadi, 2013.

Giuliani Fonrouge, Carlos. Derecho financiero, vol. I, obra actualizada por Susana Navarrine y Rubén Asorey, 7a. ed. Buenos Aires: Depalma, 2001.

Gómez Sánchez, Yolanda. El Tribunal de Cuentas: el control económico y financiero externo en el ordenamiento constitucional. Madrid: Marcial Pons, 2001.

Jiménez Tello, Pilar. "Regulación a través de la evaluación: auditoría y calidad en las Administraciones Públicas". Revista Eurolatinoamericana de Derecho Administrativo 1, No. 1 (2015).

Martínez Lago, Miguel Ángel, y otros. Lecciones de Derecho financiero y tributario, 11a. ed. Madrid: Iustel, 2015.

Pérez Royo, Fernando. Derecho financiero y tributario. Parte general, 9a. ed. Madrid: Civitas, 1999.

Queralt, Juan Martín, Carmelo Lozano, José Tejerizo y Gabriel Casado. Curso de Derecho financiero y tributario. Madrid: Tecnos, 2011.

\section{Constitución}

Constitución de la II República de 1931, art. 120.

\section{Códigos Y LEYeS}

Código Fiscal de 1963. R. O. 490, 25 de junio de 1963.

Código Orgánico de Planificación y Finanzas Públicas. R. O. 306, 22 de octubre de 2010.

Ley 035-CL. Registro Oficial 338, 18 de marzo de 1968.

Ley 10. Registro Oficial 847, 19 de junio de 1959.

Ley de Hacienda de 21 de octubre de 1863.

Ley Orgánica 6/2013, de 14 de noviembre, de creación de la Autoridad Independiente de Responsabilidad Fiscal. 
Ley Orgánica de Administración Financiera y Control, LOAFYC. R. O. 337, 16 de mayo de 1977.

Ley Orgánica de la Contraloría General del Estado. Ley No. 2002-73. Registro Oficial 595, 12 de junio de 2002.

Ley Orgánica de Presupuesto, Decreto de Emergencia No. 538. R. O. 769, 21 de marzo de 1951.

Reglamento General del Código Orgánico de Planificación y Finanzas Públicas (DE-489). $R$. O. 329, 26 de noviembre de 2010 .

\section{Decretos}

Decreto 611. R. O. 857, 31 de julio de 1975.

Decreto 1065-A. Registro Oficial 668, 28 de octubre de 1974.

Decreto-Ley 240. Registro Oficial 33, 20 de agosto de 1963, quinto considerando.

Decreto 1077. Registro Oficial 392, 17 de septiembre de 1973.

\section{Dictamen}

Dictamen de Constitucionalidad sobre las Enmiendas No. 001-14-DRC-CC, 31 de octubre de 2014, Gaceta Constitucional No. 009, 10 de noviembre de 2014.

\section{INFORMES}

Rendición de Cuentas del Contralor General del Estado, marzo de 2016.

\section{INTERNET}

Estudio introductorio a la Ley Orgánica de Administración Financiera y Control, SILEC. Disponible en 〈www.bolsadevaloresguayaquil.com〉.

Informe para segundo debate de la Comisión Ocasional de Enmiendas Constitucionales, 23 de noviembre de 2015. Disponible en 〈www.asambleanacional.gob.ec/sites/default/files/field/ image/enmienda8.jpg>.

Normas ISSAI y Directrices de Auditoría Financiera de la INTOSAI para la Buena Gobernanza (INTOSAI-GOV). Disponible en 〈www.intosai.org〉 y 〈www.olacefs.com〉. 